\title{
Biodegradation of $p$-nitrophenol by engineered strain
}

\author{
Jing $\mathrm{Xu}^{\dagger}$, Bo Wang ${ }^{\dagger}$, Wen-hui Zhang, Fu-Jian Zhang, Yong-dong Deng, Yu Wang, Jian-Jie Gao, \\ Yong-Sheng Tian * (i), Ri-He Peng* and Quan-Hong Yao*
}

\begin{abstract}
p-Nitrophenol (PNP) is an important environmental pollutant and can causes significant environmental and health risks. Compared with the traditional methods, biodegradation is a useful one to completely remove the harmful pollutants from the environment. Here, an engineered strain was first constructed by introducing PNP biodegradation pathway via the hydroquinone (HQ) pathway into Escherichia coli. In the engineered strain BL-PNP, PNP was completely degraded to $\beta$-ketoadipate and subsequently enter the metabolites of multiple anabolic pathways. The high tolerance and rapid degradation ability to PNP enable the engineered strain to have the potential to degrade toxic substances. The engineered strain created in this study can be used as a functional strain for bioremediation of PNP and potential toxic intermediates, and the method of assembling aromatic hydrocarbons metabolic pathway can be used to eradicate nitroaromatic pollutants in the environment.
\end{abstract}

Keywords: $p$-Nitrophenol, Degradation, Multigene metabolic engineering, E. coli, Bioremediation

\section{Key points}

1. Five genes of PNP biodegradation pathway were synthesized and modified.

2. All genes were regulated by monocistronic transcriptional pattern.

3. PNP and subsequent decomposition intermediates have been completely degraded.

\section{Introduction}

Nitroaromatic compounds have been widely used as dyes, pesticides, herbicides, plasticizers and explosives (Zhang et al. 2018). The presence of these nitroaromatic compounds and their subsequent release has led to severe environmental pollution of soil, ground water and

\footnotetext{
*Correspondence: tys810508@126.com; pengrihe@163.com; yaoquanhong_ sh@aliyun.com

${ }^{\dagger}$ Jing Xu and Bo Wang are contributed equally to the article

Shanghai Key Laboratory of Agricultural Genetics and Breeding,

Agro-Biotechnology Research Institute, Shanghai Academy of Agricultural

Sciences, Shanghai 201106, China
}

air. Therefore, nitroaromatic compounds has been rated as priority pollutant (as HR-3 grade) and recommended restricting its concentration to less than $10 \mathrm{ng} / \mathrm{mL}$ in the natural water bodies (US Environmental Protection Agency 1976). $p$-Nitrophenol (PNP) is an important nitroaromatic compounds, and is used in the large-scale synthesis of acetaminophen, an aspirin substitute, and in the production of pesticides such as methylparathion and parathion (Spain and Gibson 1991). In the environment, these pesticides are also considered to be a major source of PNP detected in the environment since they can be converted to PNP under the action of hydrolase (Samuel et al. 2014). PNP is considered as a persistent, toxic contaminant (Kulkarni and Chaudhari 2006; EPA 2005). The toxicology and carcinogenicity of PNP have been studied (Ahmed et al. 2015, 2021).

Different physical and chemical methods, including adsorption, electro or photo-catalyst have been used for removing these compounds (Vélez-Lee et al. 2016). But the disadvantages of these methods are sophisticated, expensive equipments and high energy consumption (Ma et al. 2014). Hence, biodegradation has been wildly
Springer Open (c) The Author(s) 2021. Open Access This article is licensed under a Creative Commons Attribution 4.0 International License, which permits use, sharing, adaptation, distribution and reproduction in any medium or format, as long as you give appropriate credit to the original author(s) and the source, provide a link to the Creative Commons licence, and indicate if changes were made. The images or other third party material in this article are included in the article's Creative Commons licence, unless indicated otherwise in a credit line to the material. If material is not included in the article's Creative Commons licence and your intended use is not permitted by statutory regulation or exceeds the permitted use, you will need to obtain permission directly from the copyright holder. To view a copy of this licence, visit http://creativecommons.org/licenses/by/4.0/. 
concerned and become a hot topic due to its safety, low cost, minimal environmental impact and no secondary pollution (Peng et al. 2014; Zheng et al. 2009). Many microorganisms capable of degrading PNP have been isolated, such as bacteria (Zhang et al. 2008; Chauhan et al. 2010; Zhang et al. 2012; Spain 1995; Perry and Zylstra 2007; Shen et al. 2010) and microalgae (Lima et al. 2003), and their degradation pathways have been studied (Fig. 1). PNP would be converted to maleylacetate via hydroquinone pathway or hydroxyquinol pathway. In hydroquinone pathway, PNP was converted to maleylacetate via four enzymes ( $p$-nitrophenol monooxygenase, benzoquinone reductase, hydroquinone 1,2-dioxygenase, dehydrogenase) which were encoded by $p n p A$ to $p n p D$, respectively. In hydroxyquinol pathway, PNP was converted to 4-nitrocatechol via $p$-nitrophenol 2 -monooxygenase, and then converted to 1,2,4-benezenetriol. Maleylacetate was converted to $\beta$-ketoadipate via maleylacetate reductase, which subsequently enters metabolites in a variety of anabolic pathways, including the TAC cycle and fatty acid biosynthesis (Wells and Ragauskas 2012).

For the first time, an E. coli strain was successfully constructed in this study to directionally degrade toxic PNP into carbon source by using the method of synthetic biology. The genes were selected from PNP-degradation bacterial Pseudomonas putida. Codons were modified and optimal designed according to the codon bias for engineered strain. Then, the PNP-degradation module containing the five genes involved in PNP degradation was constructed using $\mathrm{T} 7$ transcript system in a monocistronic transcriptional pattern. The module was then inserted into one vector after proving the bioconversion from PNP to $\beta$-ketoadipate for generating the recombinant PNP-degrading E. coli strain. In the remodeled E. coli cells, PNP was successfully converted to $\beta$-ketoadipate, and subsequently imported into the TCA cycle. The remodeled PNP-degraded strain can be used as a functional strain for the bioremediation of PNP and potential toxic intermediates. The method adopted in the study can also be used for transforming other strains or constructing engineered strains to create ones that can adapt to different environments or break down other pollutants.

\section{Materials and methods Reagents}

$p$-Nitropheol was obtained from Aladdin (http://www. aladdin-e.com/zh_cn/). $\quad \beta$-Ketoadipate was obtained from Finetech Industry Limited (Wuhan, China). All other chemicals were purchased from Sangon Biotech Co., Ltd. (Shanghai, China). Primers were synthesized from Sangon Biotech Co., Ltd. KOD DNA polymerase was purchased from TOYOBO Co., Ltd. (Osaka, Japan). Restriction enzymes were purchased from Takara Biomedical technology Co., Ltd. (Beijing, China).

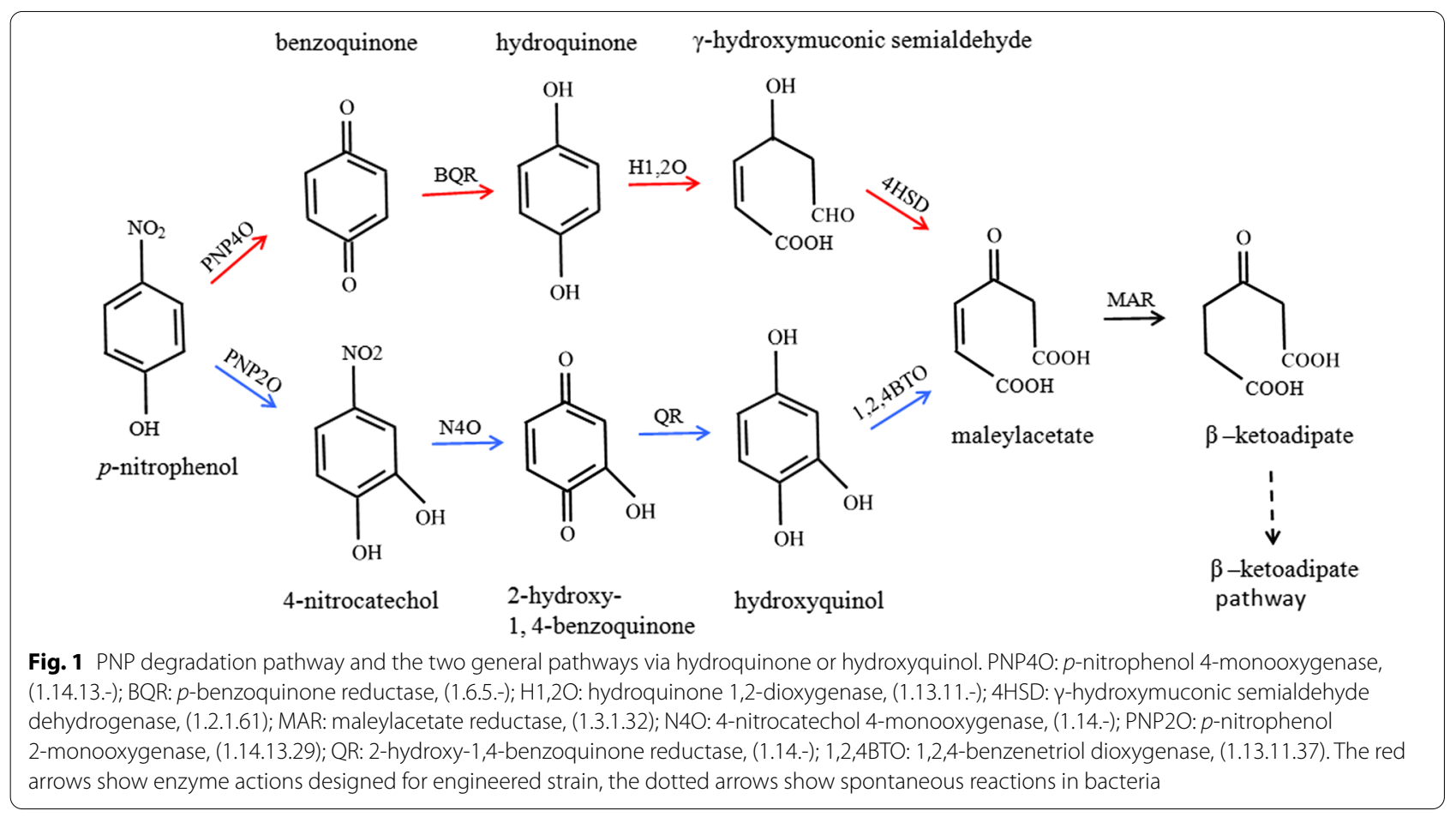




\section{Bacteria and growth condition}

The bacterium used for engineering construction was E. coli BL21-AI (Invitrogen, Waltham, MA, USA).

The basic liquid medium M9 $\left(\mathrm{Na}_{2} \mathrm{HPO}_{4} \cdot 7 \mathrm{H}_{2} \mathrm{O}\right.$, $\left.12.8 \mathrm{~g} / \mathrm{L} ; \mathrm{KH}_{2} \mathrm{PO}_{4}, 3 \mathrm{~g} / \mathrm{L} ; \mathrm{NH}_{4} \mathrm{Cl}, 1 \mathrm{~g} / \mathrm{L} ; \mathrm{NaCl}, 0.5 \mathrm{~g} / \mathrm{L}\right)$ was used to culture $E$. coli BL21-AI, supplemented with glycerin (replace glucose) of $10 \mathrm{~g} / \mathrm{L}$, casamino acids of $1 \mathrm{~g} / \mathrm{L}$ and thiamine hydrochloride of $10 \mathrm{ppm}$. In addition, the inducer isopropyl- $\beta$-D-thiogalactoside (IPTG) of $1 \mathrm{mM}$ and arabinose of $2 \mathrm{~g} / \mathrm{L}$ were also added to the medium for inducing gene expression.

Escherichia coli BL21-AI strain was incubated on a rotary shaker $\left(160 \mathrm{rpm}, 37^{\circ} \mathrm{C}\right)$. The cells were harvested by centrifugation and weighed, washed three times with M9 and then re-suspended in the prepared inoculums $\left(\mathrm{OD}_{600}=0.5\right)$ for subsequent use.

\section{Vector construction}

The conversion of PNP to $\beta$-ketoadipate requires five genes, $p n p A$ to $p n p E$. These genes from Pseudomonas putida (GenBank: FJ376608.2) were selected for chemical synthesis using PCR-based two-step DNA synthesis (PTDS) (Xiong et al. 2004). The codons of these five genes were modified and optimal designed to make them more suitable for $E$. coli. At the same time, stem loop structure, reverse repeat sequence and transcriptional terminator were eliminated to ensure mRNA stability and balance of GC content. The five synthetic genes, $p n p A, p n p B, p n p C, p n p D$ and $p n p E$ were renamed as pnpAS, pnpBS, pnpCS, $p n p D S$ and pnpES (GenBank: MZ393850, MZ393851, MZ393852, MZ393853, MZ393854, respectively).

Each synthetic gene was connected between T7 promoter and terminator respectively, and arranged in the correct order. The gene expression cassette was then constructed using the polyacrylamide gel electrophoresis (PAGE) - mediated overlap extension PCR method (Peng et al. 2006). The constructed gene expression cassettes of the five gene was designated as T7pnpAS-T7pnpBST7pnpCS-T7pnpDS-T7pnpES, abbreviated as T7pnpAS-T7pnpES. Meanwhile, EcoRI and HindIII restriction sites were added to the $5^{\prime}$ and $3^{\prime}$ end of the expression cassette. The constructed expression cassette was then inserted into the expression vector pCAMBIA1301. Finally, the five-gene construction was completed and named as pYB3847.

\section{Escherichia coli transformation}

The final pYB3847 plasmid was transformed into the host E. coli strain BL21-AI. The transformant was named as BL-PNP.

\section{Gene expression analysis}

The transformant (BL-PNP) carrying the pYB3847 plasmid with all the five genes was used for RNA extraction. After $6 \mathrm{~h}$ of induction, total RNA from the transformant BL-PNP was extracted using TRIzol reagent (Invitrogen) according to the manufacturer's instruction. Removal of genomic DNA and synthesis of cDNA was using cDNA Synthesis superMix (TransGen Biotech Co., Ltd., Beijing, China) according to the manufacturer's instruction. The fluorescent quantitative PCR reaction (RT-PCR) of five genes was performed according to the method of Wang et al. (2019). The sequences of primers for each gene used are listed in Additional file 1: Table S1.

\section{$p$-Nitrophenol biodegradation}

Different concentrations of $p$-nitrophenol ( $1 \mathrm{mM}, 5 \mathrm{mM}$, $10 \mathrm{mM}$ ) were added to the prepared bacterial suspension containing inducers to detect biodegradation capability of the transformed strains. The strains transformed with empty vector under the same conditions were used as control group. M9 medium containing inducers but without any strains was used as blank group.

\section{Analysis of main metabolites of $p$-nitrophenol degradation} Cell densities were measured with optical densities at $600 \mathrm{~nm}$ (OD600) using an Infinite 2000 (TECAN) plate reader.

The concentration of PNP and its main hydrolysis, hydroquinone $(\mathrm{HQ})$ and $\beta$-ketoadipate, were monitored over a 3-day period.

The concentration PNP and HQ were determined by High performance liquid chromatography (HPLC) using Agilent 1100 HPLC system (Agilent Technologies, CA, USA), which was equipped with Athena $5 \mu \mathrm{m} \mathrm{C18} \mathrm{col-}$ umn $(4.6 \times 150 \mathrm{~mm}, \mathrm{CNW})$ (ANPEL Inc., Shanghai, China). The tested sample was twenty microliters. For PNP analysis, the mobile phase was methanol (50:50) at a flow rate of $0.5 \mathrm{~mL} / \mathrm{min}$. For hydroquinone analysis, the mobile phase was methanol (30:70) at $0.5 \mathrm{~mL} / \mathrm{min}$. PNP and $\mathrm{HQ}$ were detected at $318 \mathrm{~nm}, 270 \mathrm{~nm}$ respectively, using ultraviolet spectrophotometric detector (Agilent 1100 VWD).

The concentration of $\beta$-ketoadipate was detected by gas chromatography mass spectrometry (GC-MS) using the method of Okamura-Abe et al. (2016) and Wang et al. (2019) with minor modification. Samples were detected after derivatization. GC-MS analysis was performed on GC-MS/MS 7890B-7000C system (Agilent) equipped with a HP-5 MS column $(30 \mathrm{~m} \times 0.25 \mathrm{~mm} \times 0.25 \mu \mathrm{m}$, Agilent). The oven parameters were: $40{ }^{\circ} \mathrm{C} / \mathrm{min}$ from 100 
to $160{ }^{\circ} \mathrm{C}, 10{ }^{\circ} \mathrm{C} / \mathrm{min}$ from 160 to $250{ }^{\circ} \mathrm{C}, 20^{\circ} \mathrm{C} / \mathrm{min}$ from 250 to $300{ }^{\circ} \mathrm{C}$.

\section{Statistical analysis}

All experiments were repeated three replicates for each sample. Statistical significance was tested by Student's t-test.

\section{Results}

\section{Identification of PNP-biodegradation genes}

PNP biodegradation pathway via the hydroquinone (HQ) pathway under aerobic conditions was chosen, the degradation pathways were shown in Fig. 1. Designing and optimizing the candidate genes to make them more suitable for $E$. coli was the first step of this experiment. Five genes, $р n p A$ to $p n p E$ for PNP degradation from Pseudomonas putida were selected for chemical synthesis, and these codons were designed and optimized according to preferential codon usage for $E$. coli in order to be conducive for improving gene expression (Additional file 1: Table S1). The identity of the synthetic genes showed $75.6 \%, 35.39 \%, 80.32 \%, 80.66 \%$ and $79.15 \%$ similarity with the original sequence.

\section{Vector construction and genetic transformation}

The T7 promoter and terminator were selected for controlling the expression of each exogenous genes, as T7 phage RNA polymerase promoter was one of the strongest expression systems for expressing exogenous genes and recombinant proteins in E. coli (Landick 2004), The monocistronic transcriptional pattern was used for constructing the artificial gene cluster, the recombinant vector, which contained five lined genes in the committed PNP biodegradation pathway, was showed in Fig. 2.

\section{Expression of exogenous genes in the engineered strain}

Genetically modification of multigene transformation is being accepted as an approach to generate microorganisms for environmental bioremediation. But the multigene vector will become more cumbersome and unstable as the increase of transgene (Zorrilla-López et al. 2013). The cDNA from the engineered strain were isolated and analyzed to verify whether the exogenous genes were

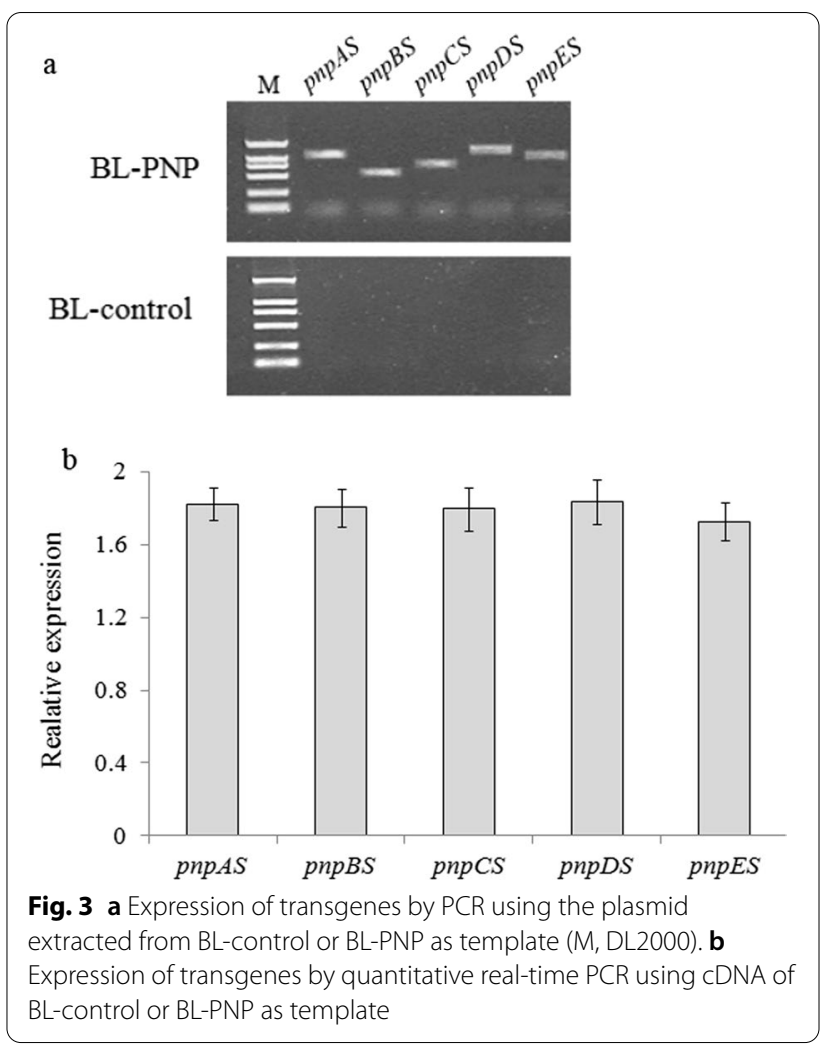

stable. Results indicated that the expression vector with five genes was successful constructed and the expression of each gene was stable (Fig. 3a). The transcript expressions of the five genes were then analyzed through Real-Time PCR. Except the wild-type strain, all the five genes can be detected in the engineered strain BL-PNP (Fig. 3b). The RT-PCR demonstrated that the five genes were stably and actively transcribed in the engineered strain BL-PNP.

\section{Analysis of PNP degradation}

The degradation ability of engineered strain BL-PNP at high concentrations of PNP was studied by treating them with different concentration of PNP. As shown in Fig. 4, PNP was completely degraded within $8 \mathrm{~h}$ and $24 \mathrm{~h}$ from

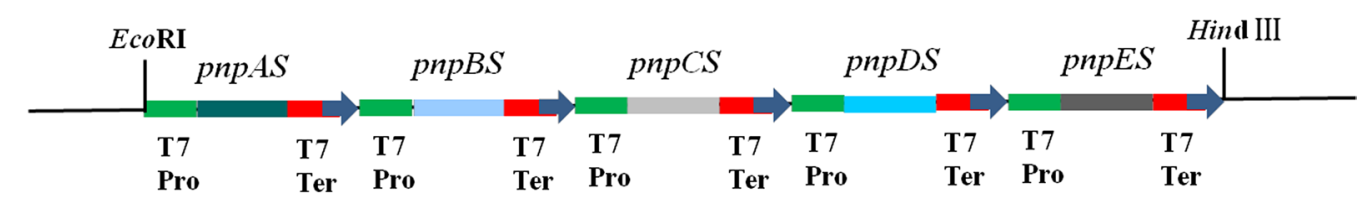

Fig. 2 Schematic representation of recombinant vectors used in E. coli transformation. pnpAS ( $p$-nitrophenol 4-monooxygenase), pnpBS ( $p$-benzoquinone reductase), pnpCS (hydroquinone 1,2-dioxygenase), pnpDS ( $\gamma$-hydroxymuconic semialdehyde dehydrogenase), pnpES (maleylacetate reductase) 


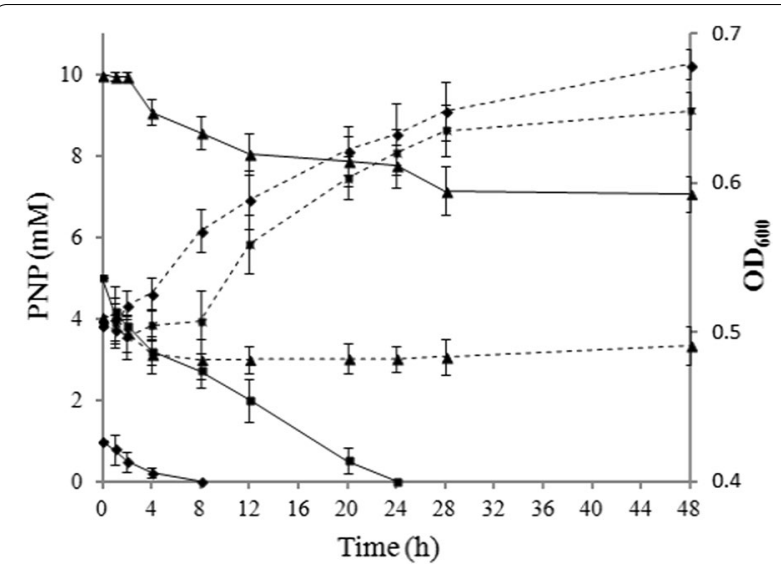

Fig. 4 Degradation of PNP with different concentrations in the engineered strain BL-PNP, and the growth of the strain in the M9 media containing different concentration of PNP. The solid lines show the degradation of PNP, and the dotted lines show the growth of the engineered strain. Black diamond, $1 \mathrm{mM}$ PNP; black square, $5 \mathrm{mM}$ PNP; black up-pointing triangle, 10 mM PNP

an initial concentration of $1 \mathrm{mM}$ and $5 \mathrm{mM}$, respectively. However, a lag period of $8 \mathrm{~h}$ was observed when the initial concentration was $5 \mathrm{mM}$. When the concentration reached $10 \mathrm{mM}$, only less than $3 \mathrm{mM}$ PNP was degraded in $24 \mathrm{~h}$, and the growth of BL-PNP was inhibited.

\section{Metabolites analysis}

In this study, the engineered strain was designed to completely degrade PNP via the pathway of hydroquinone $(\mathrm{HQ})$, thus the metabolites $\mathrm{HQ}$ and the last hydrolysis product, $\beta$-ketoadipate, were analyzed.

When the concentration of PNP was $1 \mathrm{mM}$, it can be rapidly degraded in $8 \mathrm{~h}$. At the same time, with the depletion of PNP, the concentration of HQ was increased gradually and peaked at $8 \mathrm{~h}$ (Fig. 5a). However, the amount of PNP hydrolysis and HQ generation were not stochiometric. After the peak, the concentration of HQ gradually decreased and $74 \%$ of HQ was degraded within $24 \mathrm{~h}$. It cannot be detected after $24 \mathrm{~h}$ in the degradation system.

$\beta$-Ketoadipate, the last degraded product constructed in the experiment, was also detected. When $1 \mathrm{mM}$ PNP was added to the liquid medium, the concentration of $\beta$-ketoadipate was increased slowly within the first $8 \mathrm{~h}$. It then increased rapidly within $24 \mathrm{~h}$, and peaked at $24 \mathrm{~h}$. After that, the concentration of $\beta$-ketoadipate gradually decreased (Fig. 5b). The results illustrated that the pathway for the complete degradation of PNP in E. coli has been successfully constructed, and the $\beta$-ketoadipate produced by the degradation of PNP can quickly enter into multiple anabolic pathways. Therefore, the engineered strain BL-PNP will be useful for the bioremediation of the phenolic compounds.

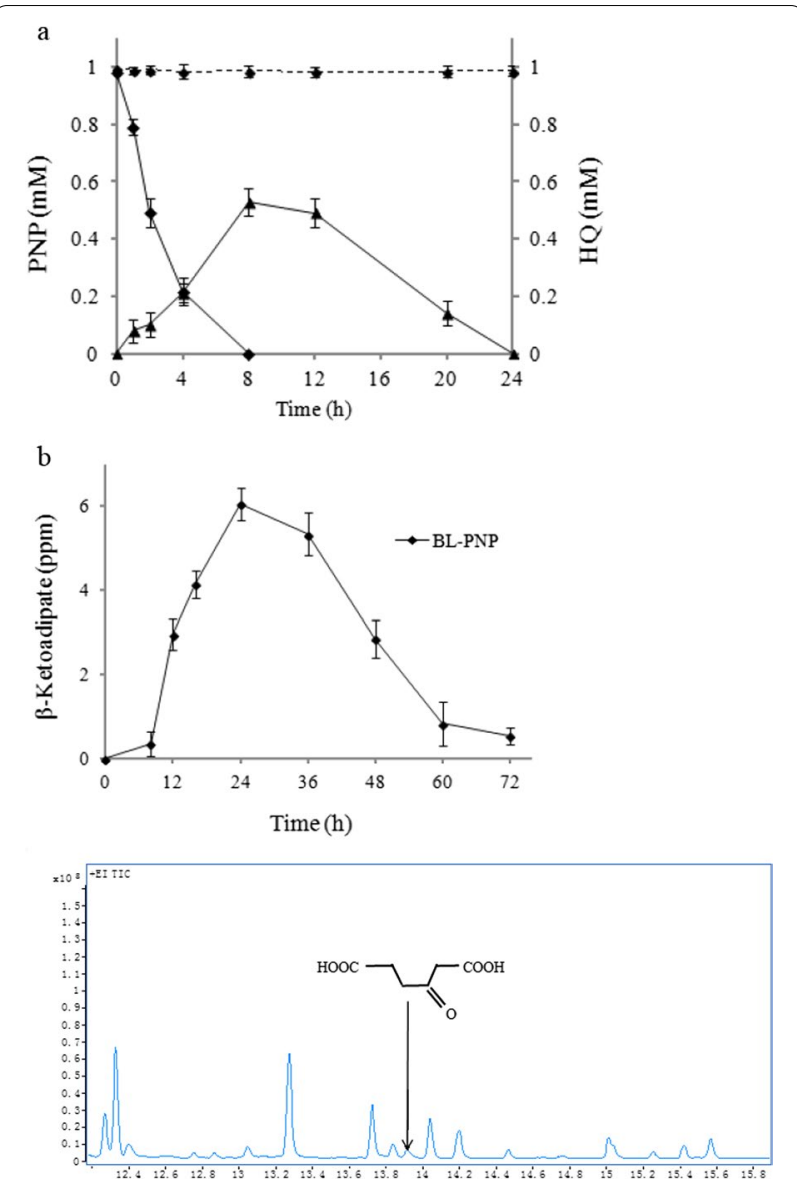

Fig. 5 Degradation of 1 mM PNP. PNP was converted to

$\beta$-ketoadipate via HQ pathway as designed. a Degradation of PNP and formation of HQ. The solid lines show the change of the metabolites in the engineered strain BL-PNP, and the dotted lines show the one in control strain. Black diamond, the degradation of PNP; black up-pointing triangle, the formation of HQ. $\mathbf{b}$ GC-MS analysis of $\beta$-ketoadipate concentration at different times in the engineered strain BL-PNP

In BL-control strain, the content of PNP was detected with the same period of time as BL-MP within 3d, and no degradation was found (Fig. 5a). The PNP hydrolysis products, hydroquinone and $\beta$-ketoadipate, were not found, neither (data not shown).

\section{Discussion}

As a commercial commodity, nitrophenols are widely used in the production of herbicides, pesticides and other aspects (Kulkarni and Chaudhari 2007), which led to serious environmental pollution. Microorganisms, especially bacteria living in various environments can grow in the environment containing nitrophenol compounds due to their unique ability, and at the same time, they also achieve the purpose of degradation of nitrophenol. 
In addition, genetically modification of bacterial strains is one of the useful tools to improve the degradation of nitroaromatic compounds (Nordin et al. 2005; Xiao et al. 2007). Thus, searching novel strains or constructing modified ones which are capable of removing environmental contaminant is a very interesting academic task (Frey and Kallio 2003). In this study, a modified strain which can completely biodegrade PNP was first constructed with modulated PNP degradation pathways by using the method of synthetic biology.

Traditionally, the way to remove toxic contaminants was to use microorganisms found in nature, but the disadvantage was that the background is too complex to effectively improve the degradation efficiency. E. coli, due to its clear background, favorable growth condition, and availability of versatile genetic manipulation tools, has become an ideal platform host for biosynthesis and biodegradation (Pósfai et al. 2006; Pontrelli et al. 2018). Biodegradation has also become easier and more suitable for engineering by establishing a series of standard biological operating units, such as promoters, operons, resistance screening markers, and some regulatory factors, etc. (McNerney et al. 2015; Anderson et al. 2010).

Metabolic engineering researches in prokaryotes are mainly based on operon modification (Chhabra and Keasling 2010). The simultaneously coordinated expression of multiple genes is the most essential requirement for the construction of multigene engineering in heterologous microbial background. In transgenic plants, multiple transgenes controlled by the same promoter have shown coordinated and stable expression when the same promoter used repeatedly for each gene (Zhu et al. 2008; Tian et al. 2020). In transgenic microorganism, the same operation can also be used to achieve the same goal, which has been demonstrated in our laboratory, where we have successfully constructed a bacterial multigene engineered strain and achieved the biodegradation of phenol (Wang et al. 2019).

Due to the cytotoxicity of PNP, most of the studies mainly focused on the degradation of PNP at lower concentrations (10 ng-150 ppm). In this study, the degradation of PNP at high concentrations was studied, and the engineered strain BL-PNP had high tolerance and rapid degradation ability among the reported PNP-degrading strain. Phenolic compounds have been reported to have exerted toxic effects on membrane owing to their high aqueous solubility (Sikkema et al. 1995), which leads to a lag phase in the degradation of high concentration of PNP. P. putida has been reported to completely degrade $300 \mathrm{ppm}$ and $500 \mathrm{ppm}$ PNP within $36 \mathrm{~h}$ and $72 \mathrm{~h}$ with a lag period of $12 \mathrm{~h}$ and $20 \mathrm{~h}$, respectively (Kulkarni and Chaudhari 2006; Samuel et al. 2014). Similar reports have been reported for other bacteria, such as
Stenotrophomonas (Liu et al. 2007), Pseudomonas aeruginosa (Zheng et al. 2009). This could be due to the antimicrobial toxicity and dose dependent of PNP (Bhushan et al. 2000; Orenes-Piñero et al. 2013). The engineered strain BL-PNP had a shorter lag phase and faster degradation rate, indicating that BL-PNP can quickly adapt to the toxic concentrations of organic substrate. These characteristics made it potentially useful for the PNP-biodegradation of high concentrations.

As designed, PNP was completely degraded via the pathway of hydroquinone (HQ), which was the common metabolic of hydroxylation of $p$-substituted phenols (Spain and Gibson 1991; Bae et al. 1996). However, the amount of PNP degradation and HQ generation were not stochiometric. This might be due to the immediate metabolism of $\mathrm{HQ}$, which was constantly produced by the hydrolysis of PNP and continuously degraded at the same time. $\beta$-Ketoadipate was designed as the last degraded product constructed in the experiment. The $\beta$-ketoadipate pathway, which is an enzyme-mediated aryl-ring degradation sequence, was widely employed by soil bacteria and fungi to convert many harmful aromatic pollutants into benign ones, including TCA (tricarboxylic acid cycle) metabolites, lipogenesis and other anabolic processes (Ju and Parales 2010). The decrease of $\beta$-ketoadipate produced by the degradation of PNP illustrated that it can quickly enter into multiple anabolic pathways and the engineered strain BL-PNP will be useful for the bioremediation of the phenolic compounds.

Here, E. coli obtained a new PNP-biodegradation function by precisely designing metabolic pathways. However, the degradation efficiency of toxic pollutants by engineered strains in the field condition could mostly insufficient compared with laboratory conditions. The main reasons are as follow: availability of oxygen and competition with autochthonous microorganisms. Therefore, it is necessary to consider some factors for biodegradation, such as location, cost, environmental types and policies, and so on (Azubuike et al. 2016). In addition, the ecological risks associated with bioremediation using engineered strains, such as gene flow, competition and fitness should also be evaluated and controlled (Kuiken et al. 2014).

\section{Supplementary Information}

The online version contains supplementary material available at https://doi. org/10.1186/s13568-021-01284-8.

Additional file 1: Table S1. The sequences of primers for respective gene used in this study.

Acknowledgements

This work was supported by the Key Project Fund of the Shanghai Municipal Committee of Agriculture (chuangzi 2018 1-5); National Natural Science Foundation of China (31901069); Shanghai Academic Technology Research Leader 
(20XD1432200; 19XD1432300); Talent Development Fund Project of Shanghai (2020101) and the "Zhu-Pao" plan of Shanghai Academy of Agricultural Sciences (ZP20211).

\section{Authors' contributions}

Q-HY and R-HP designed the research. JX, W-HZ, F-JZ, YW and Y-ST performed these experiments. BW, J-JG, Y-DD analyzed these data. JX wrote the manuscript. All authors read and approved the final manuscript.

\section{Funding}

Not applicable.

\section{Availability of data and materials}

The datasets generated during and/or analysed during the current study are available from the corresponding author on reasonable request.

\section{Declarations}

\section{Ethics approval and consent to participate}

This article does not contain any studies with animals or human participants performed by any of the authors.

\section{Consent of publication}

Not applicable.

\section{Competing interests}

All the authors declare that there is no competing interests.

Received: 28 June 2021 Accepted: 19 August 2021

Published online: 31 August 2021

\section{References}

Ahmed E, Nagaoka K, Fayez M, Samir H, Watanabe G (2015) Long-term p-nitrophenol exposure can disturb liver metabolic cytochrome P450 genes together with aryl hydrocarbon receptor in Japanese quail. Jpn J Vet Res 63(3):115-127

Ahmed EA, Khaled HE, Elsayed AK (2021) Long-term exposure to $p$-nitrophenol induces hepatotoxicity via accelerating apoptosis and glycogen accumulation in male Japanese quails. Environ Sci Pollut Res. https://doi.org/10. 1007/s11356-021-13806-9

Anderson JC, Dueber JE, Leguia M, Wu GC, Arkin AP, Keasling JD (2010) BglBricks: a flexible standard for biological part assembly. J Biol Eng 4(1):1-12. https://doi.org/10.1186/1754-1611-4-1

Azubuike CC, Chikere CB, Okpokwasili GC (2016) Bioremediation techniquesclassification based on site of application: principles, advantages, limitations and prospects. World J Microbiol Biotechnol 32(11):1-18. https:// doi.org/10.1007/s11274-016-2137-x

Bae HS, Lee JM, Lee ST (1996) Biodegradation of 4-chlorophenol via a hydroquinone pathway by Arthrobacter ureafaciens CPR706. FEMS Microbiol Lett 145(1):125-129. https://doi.org/10.1016/0378-1097(96)00400-4

Bhushan B, Chauhan A, Samanta SK, Jain RK (2000) Kinetics of biodegradation of $p$-nitrophenol by different bacteria. Biochem Biophys Res Commun 274(3):626-630. https://doi.org/10.1006/bbrc.2000.3193

Chauhan A, Pandey G, Sharma NK, Paul D, Pandey J, Jain RK (2010) p-Nitrophenol degradation via 4-nitrocatechol in Burkholderia sp. SJ98 and cloning of some of the lower pathway genes. Environ Sci Technol 44(9):34353441. https://doi.org/10.1021/es9024172

Chhabra SR, Keasling JD (2010) Metabolic design and control for production in prokaryotes. Compr Biotechnol. https://doi.org/10.1016/B978-0-08088504-9.00031-3

EPA (2005) National recommended water quality criteria table. Water. https:// doi.org/10.1201/9781420032963.axb

Frey AD, Kallio PT (2003) Bacterial hemoglobins and flavohemoglobins: versatile proteins and their impact on microbiology and biotechnology. FEMS Microbiol Rev 27(4):525-545. https://doi.org/10.1016/S0168-6445(03) 00056-1
Ju K-S, Parales RE (2010) Nitroaromatic compounds, from synthesis to biodegradation. Microbiol Mol Biol Rev 74(2):250-272. https://doi.org/ 10.1128/mmbr.00006-10

Kuiken T, Dana G, Oye K, Rejeski D (2014) Shaping ecological risk research for synthetic biology. J Environ Stud Sci 4(3):191-199. https://doi.org/ 10.1007/s13412-014-0171-2

Kulkarni M, Chaudhari A (2006) Biodegradation of $p$-nitrophenol by $P$. putida. Bioresour Technol 97(8):982-988. https://doi.org/10.1016/j.biort ech.2005.04.036

Kulkarni M, Chaudhari A (2007) Microbial remediation of nitro-aromatic compounds: an overview. J Environ Manag 85(2):496-512. https://doi. org/10.1016/j.jenvman.2007.06.009

Landick R (2004) Active-site dynamics in RNA polymerases. Cell 116(3):351353. https://doi.org/10.1016/S0092-8674(04)00121-7

Lima SAC, Castro PML, Morais R (2003) Biodegradation of $p$-nitrophenol by microalgae. J Appl Phycol 15(2-3):137-142. https://doi.org/10.1023/A: 1023877420364

Liu Z, Yang C, Qiao C (2007) Biodegradation of p-nitrophenol and 4-chlorophenol by Stenotrophomonas sp. FEMS Microbiol Lett 277(2):150-156. https://doi.org/10.1111/j.1574-6968.2007.00940.x

Ma W, Cheng Z, Gao Z, Wang R, Wang B, Sun Q (2014) Study of hydrogen gas production coupled with phenol electrochemical oxidation degradation at different stages. Chem Eng J 241 (1):167-174. https://doi.org/ 10.1016/j.cej.2013.12.031

McNerney MP, Watstein DM, Styczynski MP (2015) Precision metabolic engineering: the design of responsive, selective, and controllable metabolic systems. Metab Eng 31:123-131. https://doi.org/10.1016/j. ymben.2015.06.011

Nordin K, Unell M, Jansson JK (2005) Novel 4-chlorophenol degradation gene cluster and degradation route via hydroxyquinol in Arthrobacter chlorophenolicus A6. Appl Environ Microbiol 71(11):6538-6544. https:// doi.org/10.1128/AEM.71.11.6538-6544.2005

Okamura-Abe Y, Abe T, Nishimura K, Kawata Y, Sato-Izawa K, Otsuka Y, Nakamura M, Kajita S, Masai E, Sonoki T, Katayama Y (2016) Beta-ketoadipic acid and muconolactone production from a lignin-related aromatic compound through the protocatechuate 3,4-metabolic pathway. J Biosci Bioeng 121(6):652-658. https://doi.org/10.1016/j.jbiosc.2015.11. 007

Orenes-Piñero E, García-Carmona F, Sánchez-Ferrer Á (2013) A new process for obtaining hydroxytyrosol using transformed Escherichia coli whole cells with phenol hydroxylase gene from Geobacillus thermoglucosidasius. Food Chem 139(1-4):377-383. https://doi.org/10.1016/j.foodc hem.2012.12.063

Peng RH, Xiong AS, Yao QH (2006) A direct and efficient PAGE-mediated overlap extension PCR method for gene multiple-site mutagenesis Appl Microbiol Biotechnol 73(1):234-240. https://doi.org/10.1007/ s00253-006-0583-3

Peng RH, Fu XY, Tian YS, Zhao W, Zhu B, Xu J, Wang B, Wang LJ, Yao QH (2014) Metabolic engineering of Arabidopsis for remediation of different polycyclic aromatic hydrocarbons using a hybrid bacterial dioxygenase complex. Metab Eng 26:100-110. https://doi.org/10. 1016/j.ymben.2014.09.005

Perry LL, Zylstra GJ (2007) Cloning of a gene cluster involved in the catabolism of $p$-nitrophenol by Arthrobacter sp. strain JS443 and characterization of the $p$-nitrophenol monooxygenase. J Bacteriol 189(21):75637672. https://doi.org/10.1128/JB.01849-06

Pontrelli S, Chiu TY, Lan El, Chen FYH, Chang P, Liao JC (2018) Escherichia coli as a host for metabolic engineering. Metab Eng 50:16-46. https://doi. org/10.1016/j.ymben.2018.04.008

Pósfai G, Plunkett G, Fehér T, Frisch D, Keil GM, Umenhoffer K, Kolisnychenko V, Stahl B, Sharma SS, de Arruda M, Burland V, Harcum SW, Blattner FR (2006) Emergent properties of reduced-genome Escherichia coli. Science 312(5776):1044-1046. https://doi.org/10.1126/science.1126439

Samuel MS, Sivaramakrishna A, Mehta A (2014) Bioremediation of p-nitrophenol by Pseudomonas putida 1274 strain. J Environ Health Sci Eng 12(53):1-8. https://doi.org/10.1186/2052-336X-12-53

Shen W, Liu W, Zhang J, Tao J, Deng H, Cao H, Cui Z (2010) Cloning and characterization of a gene cluster involved in the catabolism of p-nitrophenol from Pseudomonas putida DLL-E4. Bioresour Technol 101(19):7516-7522. https://doi.org/10.1016/j.biortech.2010.04.052 
Sikkema J, De Bont JAM, Poolman B (1995) Mechanisms of membrane toxicity of hydrocarbons. Microbiol Rev 59(2):205-210. https://doi.org/10.1128/ mmbr.59.2.201-222.1995

Spain JC (1995) Biodegradation of nitroaromatic compounds. Annu Rev Microbiol 49:523-555. https://doi.org/10.1146/annurev.mi.49.100195.002515

Spain JC, Gibson DT (1991) Pathway for biodegradation of $p$-nitrophenol in a Moraxella sp. Appl Environ Microbiol 57(3):812-819. https://doi.org/10. 1128/aem.57.3.812-819.1991

Tian YS, Fu XY, Yang ZQ, Wang B, Gao JJ, Wang MQ, Xu J, Han HJ, Li ZJ, Yao QH, Peng RH (2020) Metabolic engineering of rice endosperm for betanin biosynthesis. New Phytol 225(5):1915-1922. https://doi.org/10.1111/nph. 16323

US Environmental Protection Agency (1976) Water quality criteria. US Environ. Prot. Agency, Washington, DC. https://www.epa.gov/sites/default/files/ 2018-10/documents/quality-criteria-water-1976.pdf

Vélez-Lee AE, Cordova-Lozano F, Bandala ER, Sanchez-Salas JL (2016) Cloning and expression of vgb gene in Bacillus cereus, improve phenol and p-nitrophenol biodegradation. Phys Chem Earth 91:38-45. https://doi. org/10.1016/j.pce.2015.10.017

Wang B, Xu J, Gao JJ, Fu XY, Han HJ, Li ZJ, Wang LJ, Tian YS, Peng RH, Yao QH (2019) Construction of an Escherichia coli strain to degrade phenol completely with two modified metabolic modules. J Hazard Mater 373:29-38. https://doi.org/10.1016/j.jhazmat.2019.03.055

Wells T, Ragauskas AJ (2012) Biotechnological opportunities with the ß-ketoadipate pathway. Trends Biotechnol 30(12):627-637. https://doi. org/10.1016/j.tibtech.2012.09.008

Xiao Y, Zhang JJ, Liu H, Zhou NY (2007) Molecular characterization of a novel ortho-nitrophenol catabolic gene cluster in Alcaligenes sp. strain NyZ215. J Bacteriol 189(18):6587-6593. https://doi.org/10.1128/JB.00654-07

Xiong AS, Yao QH, Peng RH, Li X, Fan HQ, Cheng ZM, Li Y (2004) A simple, rapid, high-fidelity and cost-effective PCR-based two-step DNA synthesis method for long gene sequences. Nucleic Acids Res 32(12):e98. https:// doi.org/10.1093/nar/gnh094

Zhang J, Xin Y, Liu H, Wang S, Zhou N (2008) Metabolism-independent chemotaxis of Pseudomonas sp. strain WBC-3 toward aromatic compounds. J Environ Sci 20(10):1238-1242. https://doi.org/10.1016/S1001-0742(08) 62215-9

Zhang S, Sun W, Xu L, Zheng X, Chu X, Tian J, Wu N, Fan Y (2012) Identification of the para-nitrophenol catabolic pathway, and characterization of three enzymes involved in the hydroquinone pathway, in Pseudomonas sp. 1-7. BMC Microbiol 12(27):1-11. https://doi.org/10.1186/1471-2180-12-27

Zhang CL, Yu YY, Fang Z, Naraginti S, Zhang Y, Yong YC (2018) Recent advances in nitroaromatic pollutants bioreduction by electroactive bacteria. Process Biochem 70:129-135. https://doi.org/10.1016/j.procbio.2018.04.019

Zheng Y, Liu D, Liu S, Xu S, Yuan Y, Xiong L (2009) Kinetics and mechanisms of $p$-nitrophenol biodegradation by Pseudomonas aeruginosa HS-D38. J Environ Sci 21(9):1194-1199. https://doi.org/10.1016/S1001-0742(08) 62403-1

Zhu C, Naqvi S, Breitenbach J, Sandmann G, Christou P, Capell T (2008) Combinatorial genetic transformation generates a library of metabolic phenotypes for the carotenoid pathway in maize. Proc Natl Acad Sci USA 105(47):18232-18237. https://doi.org/10.1073/pnas.0809737105

Zorrilla-López U, Masip G, Arjó G, Bai C, Banakar R, Bassie L, Berman J, Farré G, Miralpeix B, Pérez-Massot E, Sabalza M, Sanahuja G, Vamvaka E, Twyman RM, Christou P, Zhu C, Capell T (2013) Engineering metabolic pathways in plants by multigene transformation. Int J Dev Biol 57(6-8):565-576. https://doi.org/10.1387/ijdb.130162pc

\section{Publisher's Note}

Springer Nature remains neutral with regard to jurisdictional claims in published maps and institutional affiliations.

\section{Submit your manuscript to a SpringerOpen ${ }^{\odot}$ journal and benefit from:}

- Convenient online submission

- Rigorous peer review

- Open access: articles freely available online

- High visibility within the field

- Retaining the copyright to your article

Submit your next manuscript at $\boldsymbol{\nabla}$ springeropen.com 